\title{
Montagem e estudo de um quimiossensor cromogênico para a detecção de cianeto e de álcoois utilizando um ácido borônico como receptor e um corante solvatocrômico como unidade sinalizadora
}

\author{
Fabíola Maria Testoni; Samya Maren Schuhmacher; Lizandra Maria \\ Zimmermann-Dimer; Jaqueline Nicolini \& Vanderlei Gageiro Machado* \\ Departamento de Química, Centro de Ciências Exatas e Naturais, Universidade Regional de \\ Blumenau - FURB, CP 1507, Blumenau, CEP 89010-971. * gageiro@furb.br
}

\begin{abstract}
Resumo: Estudos foram realizados para analisar o comportamento do ácido fenil borônico (AB) em acetonitrila na presença da merocianina de Brooker (MB) e do corante de Reichardt. Verificou-se, por exemplo, que a adição de AB a uma solução de $\mathbf{M B}$ fez desaparecer a banda solvatocrômica do corante em 571,0 nm simultaneamente ao aparecimento de outra banda em 385,9 nm. Sugeriu-se que em excesso de AB, o complexo predominante apresenta uma estequiometria AB-MB 1:1, mas que se a concentração de AB for diminuída, uma mistura de três complexos, AB-MB, AB-(MB) $)_{2}$ e AB-(MB) $)_{3}$, é obtida. Foi verificado que o sistema AB-MB pode ser usado eficientemente como um quimiossensor para o fluoreto e para o cianeto, pois somente os dois ânions, dentre os vários estudados, tornaram violeta a solução incolor de AB-MB. Isto se deve ao fato de que estes ânions são ótimos nucleófilos e podem interagir eficazmente com o centro de boro, deslocando nucleofilicamente a $\mathbf{M B}$, que pode assim colorir a solução. Ensaios também foram realizados para a montagem de um quimiossensor cromogênico para detecção de álcoois, usando-se AB e a MB. Foi observado que o complexo AB-MB atua eficientemente como quimiossensor cromogênico, permitindo a discriminação entre álcoois primários, secundários e terciários. Esta discriminação visual pode ser explicada pelo fato de que, com o aumento do impedimento estéreo no álcool, a interação com o centro de boro fica dificultada, tornando a reação mais lenta.
\end{abstract}

Palavras-chave : quimiossensor cromogênico, detecção visual, merocianina de Brooker, álcoois, cianeto

\section{Introdução}

Uma área de pesquisa em química que tem despontado muito recentemente vem enfocando a noção de que é possível o planejamento molecular de quimiossensores para finalidades analíticas. ${ }^{1-3} \mathrm{~A}$ obtenção de um quimiossensor é possível se a molécula ou o complexo supramolecular for planejado para conter um sítio ao qual o analito possa se ligar e outro sítio que sinalize a presença do analito ligado, como um cromóforo, um fluoróforo ou um centro ativo redox. ${ }^{3}$ Quando o analito se associa ao sítio de ligação, ocorre uma perturbação no microambiente do quimiossensor que se traduz em mudanças nas propriedades do sítio de sinalização. Assim, por exemplo, se este sítio sinalizador é um grupo cromóforo, a associação do analito é indicada pela coloração devido à mudança das propriedades espectrais do centro sinalizador. Se o sítio de sinalização é um fluoróforo, a associação provoca mudanças no seu rendimento quântico e/ou no seu máximo de emissão. A literatura recente vem apontando uma quantidade crescente de quimiossensores fluorogênicos e cromogênicos para ânions, ${ }^{3-13}$

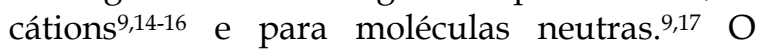
quimiossensor óptico mais simples que se pode imaginar envolve o planejamento de uma molécula que apresenta um sítio de interação com o analito. A associação desta molécula receptora com $\mathrm{o}$ analito modifica suas propriedades espectrais e indica qualitativa e quantitativamente a presença da espécie a ser detectada. É crucial neste caso o planejamento do sítio de reconhecimento de maneira a tornar o receptor seletivo para determinada espécie química e que sua associação ao receptor provoque uma mudança espectral perceptível, 
preferencialmente a olho nu. Diversos trabalhos recentes têm enfocado esta família de quimiossensores. ${ }^{15,16,18}$ Outra estratégia que vem sendo bastante explorada por diversos grupos de pesquisa envolve $\mathrm{o}$ reconhecimento $\mathrm{e}$ monitoramento de espécies químicas através do uso de ensaios de competição por receptores usando-se as técnicas de UV-vis. A linha mestra para este tipo de quimiossensor envolve o emprego de uma unidade sinalizadora, colorida em solução, que ao ser posta em contato com um receptor forma um complexo receptor:substrato. Este complexo muda as propriedades físico-químicas da unidade sinalizadora e isto se traduz por uma coloração diferente em solução. Se ao meio for adicionada uma espécie química que forma com o receptor um complexo que apresenta uma constante de estabilidade de valor mais alto que aquela do receptor com a unidade sinalizadora, esta será liberada e a solução voltará a ter o aspecto anterior à adição do receptor. Se o receptor apresenta seletividade para determinada espécie química, tem-se deste modo um quimiossensor analítico seletivo. 6,7

As merocianinas solvatocrômicas são compostos que apresentam a faculdade de mudar de cor se a polaridade do meio é alterada. ${ }^{19-21}$ Merece ser destacado que corantes solvatocrômicos, tais como a merocianina de Brooker (MB) ${ }^{22}$ e o 2,6-difenil-4(2,4,6-trifenilpiridinio)fenolato, mais conhecido como o corante de Reichardt (CR), ${ }^{21}$ podem ser utilizados como unidades sinalizadoras para a montagem de diferentes quimiossensores cromogênicos. Assim, estes corantes vêm sendo estudados em metodologias de análise apresentando resultados bastante promissores para a montagem de quimiossensores cromogênicos para ânions ${ }^{23-25} \mathrm{e}$ analitos neutros. ${ }^{26}$

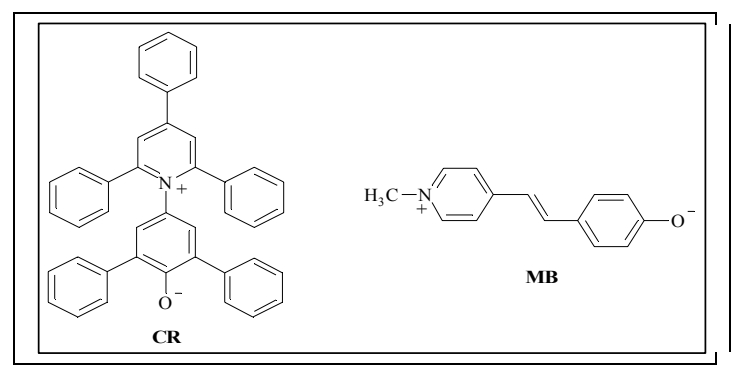

Os ácidos borônicos, tais como o ácido fenil borônico (AB), são unidades de reconhecimento eficientes, em especial para monossacarídeos 27,28 e para os ânions cianeto e fluoreto. ${ }^{29}$ A interação destes substratos com os receptores envolve a formação de ligações covalentes dos grupos hidroxílicos nos açúcares e dos ânions com o centro de boro. Assim, muitos trabalhos têm utilizado ácidos borônicos como unidades de reconhecimento em quimiossensores cromogênicos e fluorogênicos. ${ }^{27-29}$

Recentemente, foi demonstrado que uma solução da MB em acetonitrila, originalmente de cor violeta, foi descolorida pela adição de $\mathbf{A B}$ devido à formação de um complexo covalente reversível AB-MB (Esquema 1). ${ }^{25}$ A seguir, foram adicionados vários ânions e foi verificado que somente o fluoreto foi capaz de fazer retornar a coloração original da solução. Isto se deveu ao fato de que o ânion atua como nucleófilo e, ao atacar o centro de boro, provoca a saída da MB. ${ }^{25}$ Assim, o presente trabalho teve por objetivo investigar a aplicação do sistema montado entre $\mathbf{A B}$ e $\mathbf{M B}$ como quimiossensor cromogênico para cianeto e para álcoois. Os estudos foram explorados em solução usando-se como solvente a acetonitrila e foram ainda analisadas as possíveis interações da $\mathbf{M B}$ e de CR com AB.

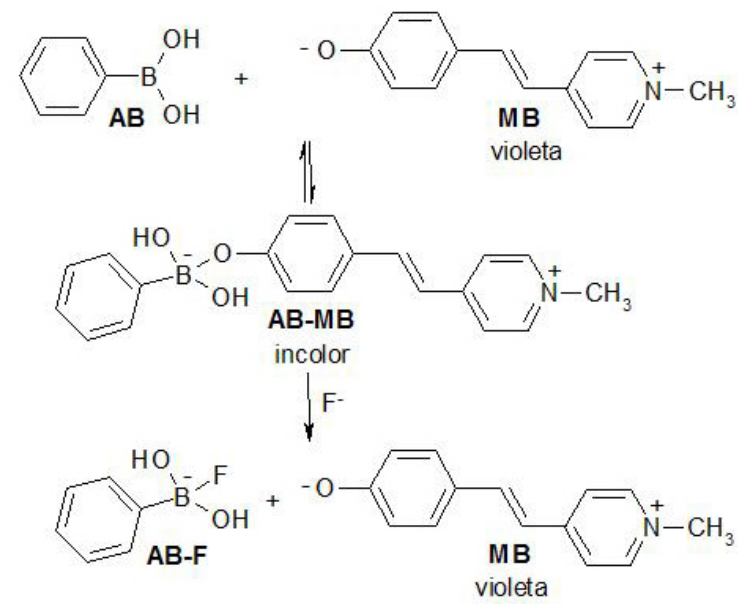

Esquema 1

\section{Material e Métodos}

Os solventes empregados nos estudos foram purificados de acordo com a metodologia descrita na literatura ${ }^{30}$ e armazenados sobre peneira molecular. Empregou-se nos estudos AB de procedência Aldrich e os corantes solvatocrômicos $\mathbf{C R}^{31}$ e $\mathbf{M B}^{32}$ foram sintetizados conforme descrição contida na literatura. Os sais de tetrabutilamônio (fluoreto, cianeto, cloreto, 
brometo, iodeto, nitrato, di-hidrogenofosfato e hidrogenossulfato) empregados nos ensaios foram de procedência Aldrich. Para a leitura dos espectros, foi utilizado um espectrofotômetro de UV-vis da Varian modelo Cary Bio 50A.

\subsection{Interação do ácido borônico com os corantes solvatocrômicos}

Primeiramente, foram preparadas soluções de MB $\left(2,0 \times 10^{-5} \mathrm{~mol} / \mathrm{L}\right)$ em acetonitrila, e então, estas soluções foram usadas na preparação da solução estoque do $\mathbf{A B}\left(5,0 \times 10^{-3} \mathrm{~mol} / \mathrm{L}\right)$. Logo após, foram adicionadas com uma microsseringa quantidades crescentes da solução contendo $\mathbf{A B}$ à solução da $\mathbf{M B}$ colocada previamente em uma cubeta de quartzo fechada com um septo de borracha e termostatizada a $25^{\circ} \mathrm{C}$. O espectro de UV-vis foi coletado após cada adição. Outro experimento foi realizado fazendose a titulação de uma solução de $\mathbf{A B}$ usando-se uma solução da MB. Para ambos os experimentos, foram coletadas as absorbâncias correspondentes à banda solvatocrômica da MB em 571,0 nm.

Finalmente, foram feitos estudos similares aos realizados para a $\mathbf{M B}$ utilizando soluções de $\mathbf{C R}$ e de $\mathbf{A B}$ em acetonitrila. Neste caso, as absorbâncias foram coletadas em $626,0 \mathrm{~nm}$, que corresponde ao máximo no comprimento de onda na região visível para o corante no solvente utilizado.

2.2. Montagem do quimiossensor cromogênico baseado em ensaios de competição entre o ânion e a MB pelo ácido borônico

Foram preparados $25 \mathrm{~mL}$ de solução contendo $\mathbf{M B}$ em acetonitrila, com concentração igual a 1,0 $\times 10^{-5}$ mol/L. Foi preparada, a partir desta solução, outra solução contendo $\mathbf{A B}$ em concentração igual a $2,78 \times 10^{-4} \mathrm{~mol} / \mathrm{L}$. Parte desta solução foi utilizada para o preparo de $2 \mathrm{~mL}$ de cada solução de diferentes sais de tetrabutilamônio, sob concentração igual a $1,0 \times 10^{-4} \mathrm{~mol} / \mathrm{L}$. Os espectros de UV-vis foram feitos em seguida e registrados. Os experimentos de titulação foram efetuados preparando-se uma solução estoque contendo o fluoreto em uma concentração igual a $7,90 \times 10^{-3}$ $\mathrm{mol} / \mathrm{L}$ usando outra solução contendo $\mathbf{M B}\left(1,0 \times 10^{-5}\right.$ $\mathrm{mol} / \mathrm{L})$ e $\mathbf{A B}\left(2,78 \times 10^{-4} \mathrm{~mol} / \mathrm{L}\right)$. Foi adicionada à cubeta, hermeticamente fechada com septo de borracha, a solução do complexo AB-MB em acetonitrila. Com o auxílio de uma microsseringa, foram feitas adições da solução contendo o ânion e após cada adição foi feita a leitura espectral em $571,0 \mathrm{~nm}$.
Os dados obtidos da titulação de AB-MB com fluoreto foram ajustados com o uso da seguinte equação: $33 \quad A b s=A b s_{0}+\left(A b s_{\max }-A b s_{0}\right) / 2 C_{\mathbf{M B}}$ $\left\{C_{\mathrm{MB}}+C_{\mathrm{F}-}+1 / K-\left[\left(C_{\mathrm{MB}}+C_{\mathrm{F}-}+1 / K\right)^{2}-4 C_{\mathrm{MB}} C_{\mathrm{F}-}\right.\right.$ ]$\left.^{1 / 2}\right\}$. Nesta equação, $A b s$ é o valor da absorbância após cada adição do ânion, $A b s_{0}$ é a absorbância inicial sem o ânion adicionado, $A b s_{\max }$ é o valor máximo de absorbância obtido pela adição do ânion, $C_{M B}$ é a concentração da MB, $C_{F-}$ é a concentração de fluoreto em cada adição e $K$ é a constante de ligação. $\mathrm{O}$ valor de $\chi^{2}$ para o ajuste foi de $4 \times 10^{-5}$.

Os ácidos borônicos são unidades eficientes para o reconhecimento dos ânions cianeto e fluoreto. ${ }^{29}$ Devido à toxicidade do cianeto, os estudos de viabilização foram feitos substituindo o cianeto pelo fluoreto. Após o acerto das condições experimentais, o cianeto foi utilizado como ânion a ser analisado.

\subsection{Cuidados a serem observados com o cianeto}

Os cianetos são bastante tóxicos e podem ser letais se inalados ou ingeridos. Os primeiros socorros às vítimas intoxicadas por cianeto estão bem descritos na literatura. ${ }^{34}$ Assim, os estudos efetuados com o cianeto foram realizados com muito cuidado, usando-se uma solução estoque do ânion preparada em acetonitrila e armazenada em um pequeno frasco vedado com um septo de borracha. As pequenas alíquotas usadas nos ensaios foram obtidas a partir destas soluções-estoque por meio de uma microsseringa. As soluções, logo após a sua utilização, foram descartadas em um frasco com água em $\mathrm{pH}$ básico, para evitar a formação de cianeto de hidrogênio. Todos os resíduos das experiências foram destruídos imediatamente após cada experimento pela adição, às soluções contendo cianeto, de uma solução de hidróxido de sódio a $10 \%$ em quantidade suficiente para que o meio fosse mantido fracamente alcalino, seguido da adição de alvejante doméstico. ${ }^{35}$

2.4. Montagem do quimiossensor cromogênico baseado em ensaios de competição entre o álcool e a MB pelo ácido borônico

A partir dos estudos anteriores puderam-se determinar as melhores condições para a montagem de um quimiossensor cromogênico para álcoois. Primeiramente, foram preparados $25 \mathrm{~mL}$ de uma solução em acetonitrila contendo MB $\left(1,0 \times 10^{-5} \mathrm{~mol} / \mathrm{L}\right)$ e $\mathbf{A B}\left(2,78 \times 10^{-4} \mathrm{~mol} / \mathrm{L}\right)$. 
Foram colocados $2 \mathrm{~mL}$ desta solução em diversos frascos fechados e a cada um deles foi adicionado, com uma microsseringa, o álcool, para uma concentração final em cada frasco igual a 0,26 $\mathrm{mol} / \mathrm{L}$. Foram utilizados os seguintes álcoois: metanol, etanol, propan-2-ol e 2-metil-propan-2-ol, a fim de se verificar o reaparecimento da banda solvatocrômica da MB. Foram feitas a seguir fotos das soluções e os espectros de UV-vis foram registrados.

\section{Resultados e Discussão}

A Figura 1 apresenta o efeito da adição de quantidades crescentes de $\mathbf{A B}$ sobre o espectro da MB em acetonitrila. Pode ser observado que a adição do ácido borônico leva em todos os casos à diminuição dos valores das absorbâncias correspondendo à banda solvatocrômica do corante em 571,0 nm seguido do aparecimento de uma nova banda em $385,9 \mathrm{~nm}$. Foi observado ainda um ponto isosbéstico em 470,1 nm, o que sugere a presença de duas espécies em equilíbrio em solução. Este efeito não pode ser explicado pela formação de complexos formados por ligações de hidrogênio (LH) entre $\mathbf{A B}$ e MB em acetonitrila. Sabe-se que a adição de um doador de LH (DLH) em uma solução da MB em acetonitrila causa deslocamento hipsocrômico na banda solvatocrômica da $\mathbf{M B}$, devido à interação específica do grupo $\mathrm{OH}$ do solvente $\mathrm{DLH}$ com o grupo fenolato doador da MB. ${ }^{36}$ No entanto, este efeito não é tão expressivo quanto o observado aqui: enormes quantidades de solvente DLH são necessárias para causar um forte deslocamento hipsocrômico, mas sem desaparecimento da banda solvatocrômica na região visível e com a ausência do ponto isosbéstico. Assim, os resultados apontam para a formação de um complexo AB-MB formado por meio de ligação covalente entre o oxigênio do grupo fenolato da $\mathbf{M B}$ e o centro de boro do $\mathbf{A B}$.

O conjunto de espectros da Figura 1 foi usado para a construção do gráfico mostrado na Figura 2, dos valores das absorbâncias em $571,0 \mathrm{~nm}$ em função da concentração do $\mathbf{A B}$ adicionado. $O$ formato do gráfico sugere um equilíbrio em solução entre múltiplas espécies formadas pela interação do $\mathbf{A B}$ com a MB. O gráfico apresenta três regiões distintas: na primeira parte, em concentrações muito pequenas de $\mathbf{A B}$, predomina o complexo $\mathbf{A B}-$ $(\mathrm{MB})_{3}$. Na região referente ao excesso de ácido borônico, em que o valor da absorbância da MB em $571,0 \mathrm{~nm}$ aproxima-se de zero, predomina o complexo AB-MB. $\mathrm{O}$ formato da região intermediária do gráfico sugere uma mistura formada pelos complexos AB-MB, AB-(MB) $)_{2} \mathrm{e}$ $\mathrm{AB}-(\mathrm{MB})_{3}$.

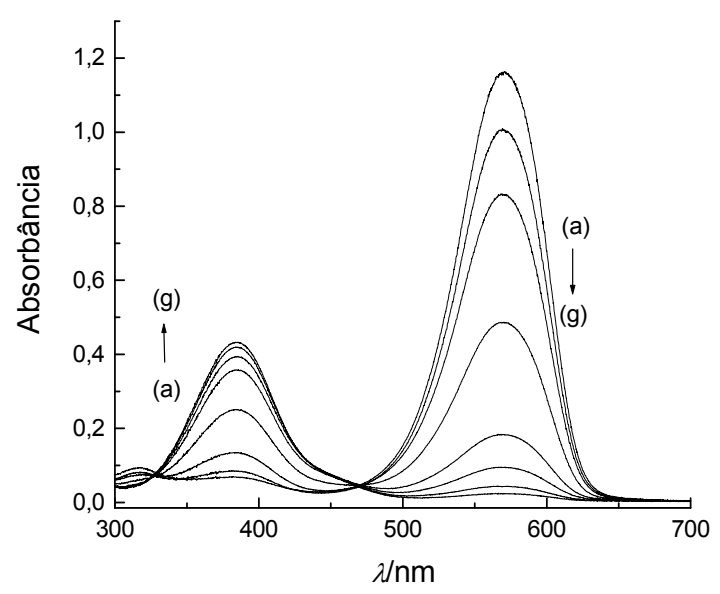

Figura 1 - Espectros de UV-vis a $25^{\circ} \mathrm{C}$ para a MB $\left(2,0 \times 10^{-5}\right.$ mol/L) em acetonitrila contendo $\mathbf{A B}$ em concentrações de: (a) zero; (b) $1,2 \times 10^{-5} \mathrm{~mol} / \mathrm{L}$, (c) $6,2 \times 10^{-5} \mathrm{~mol} / \mathrm{L}$, (d) $1,1 \times 10^{-4} \mathrm{~mol} / \mathrm{L}$, (e) $1,5 \times 10^{-4} \mathrm{~mol} / \mathrm{L}$, (f) $1,7 \times 10^{-4} \mathrm{~mol} / \mathrm{L} \mathrm{e} \mathrm{(g)} 2,4 \times 10^{-4} \mathrm{~mol} / \mathrm{L}$.

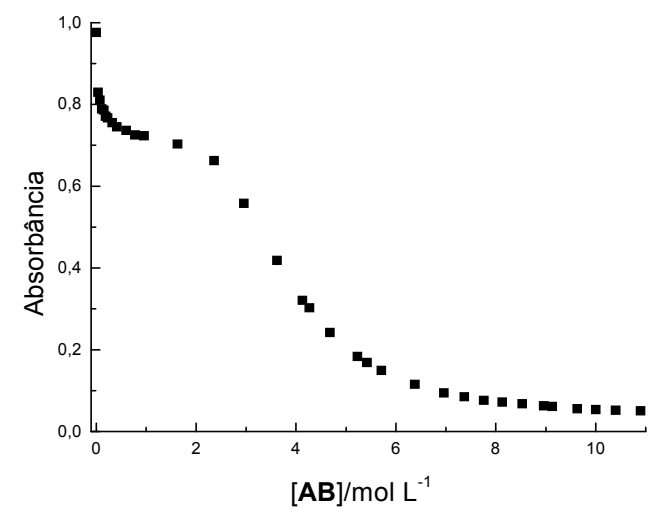

Figura 2 - Variação nos valores de absorbância para a banda solvatocrômica da MB em acetonitrila com adições crescentes de AB. A concentração do corante foi de $2,0 \times 10^{-5} \mathrm{~mol} / \mathrm{L}$ e as absorbâncias foram coletadas em $571,0 \mathrm{~nm}$.

A Figura 3 apresenta o efeito da adição da MB em concentrações crescentes a uma solução contendo AB em concentração constante. $\mathrm{O}$ gráfico demonstra que a adição de até dois equivalentes da MB não provocou qualquer alteração no valor da absorbância em $571,0 \mathrm{~nm}$, o que significa que a MB adicionada, naquelas condições, reage com o AB. 


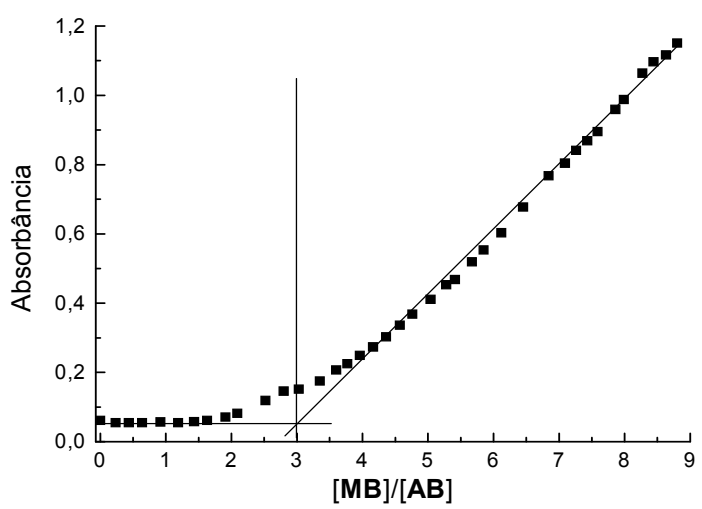

Figura 3 - Efeito da adição da MB a uma solução contendo AB $\left(1,0 \times 10^{-5} \mathrm{~mol} / \mathrm{L}\right)$ em acetonitrila. Os dados foram obtidos seguindo-se a variação da absorbância em 571,0 nm.

Somente começa-se a observar um aumento na absorbância a partir da adição de dois equivalentes da MB. Este aumento é pequeno até em torno de 3,5 equivalentes e a partir daí ocorre um aumento muito significativo no valor da absorbância. Os dados permitiram a determinação da estequiometria do complexo em condições de excesso da MB e demonstram que nestas condições ocorre a formação do complexo AB-(MB) ${ }_{3}$, corroborando as observações feitas a partir da análise da primeira parte da curva mostrada na Figura 1.

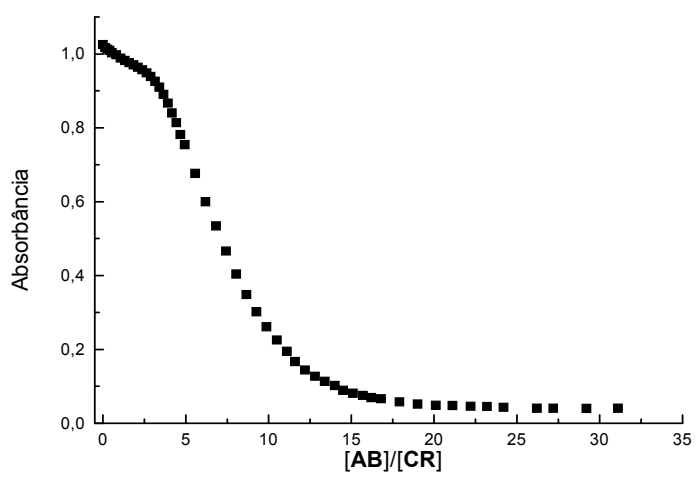

Figura 4 - Variação da absorbância em 626,0 nm para a solução de $\mathbf{C R}\left(2,0 \times 10^{-4} \mathrm{~mol} / \mathrm{L}\right)$ em acetonitrila com adições crescentes de $\mathbf{A B}$.

A Figura 4 ilustra o efeito da adição de quantidades crescentes de $\mathbf{A B}$ sobre uma solução contendo $\mathbf{C R}$ em acetonitrila. Os dados demonstram que a adição de 20 equivalentes de $\mathbf{A B}$ foram suficientes para a redução nos valores de absorbância para o valor mínimo e apontam para o fato de que em quase toda a extensão do gráfico ocorre formação do complexo AB-CR em uma estequiometria igual a 1:1.

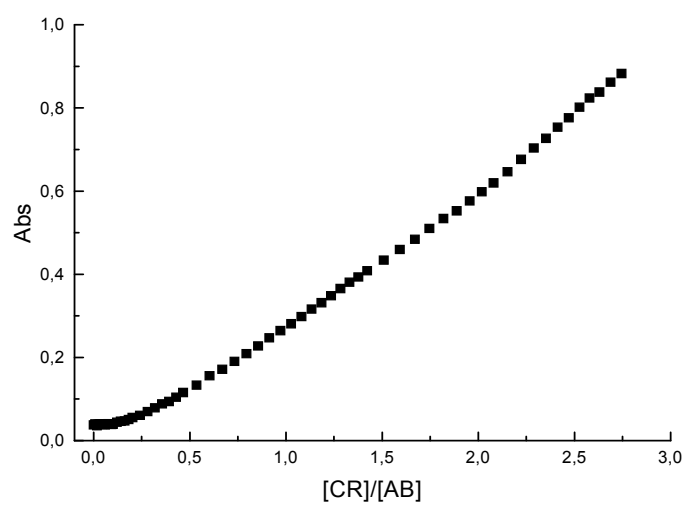

Figura 5 - Variação da absorbância em $626,0 \mathrm{~nm}$ da solução de AB $\left(1,0 \times 10^{-5} \mathrm{~mol} / \mathrm{L}\right)$ em acetonitrila com adições crescentes de $\mathbf{C R}$ até a formação do complexo AB-CR.

$\mathrm{Na}$ parte do gráfico desde zero até 2,5 equivalentes de $\mathbf{A B}$, pode-se observar uma inflexão que sugere a presença de um complexo do tipo AB-(CR) 2 .

Assim, foi realizado um experimento de titulação de uma solução de $\mathbf{A B}$ em acetonitrila com concentrações crescentes de CR (Figura 5), tendo sido verificado apenas uma estequiometria do tipo 1:1, o que sugere que se o complexo AB-(CR $)_{2}$ se forma, ele ocorre no meio em uma proporção bastante pequena. Esta diferença observada para os dois corantes estudados encontra explicação no fato de que a estrutura do CR apresenta dois grupos fenila nas posições 2 e 6 do grupo fenolato, o que deve resultar em um impedimento estéreo que dificulta sobremaneira a reação da segunda e da terceira molécula do corante com o centro de boro do AB.

\subsection{Estudo de um quimiossensor cromogênico para o cianeto}

Quantidades crescentes de diferentes ânions ( $\mathrm{F}^{-}$, $\mathrm{Cl}^{-}, \mathrm{Br}-, \mathrm{I}-\mathrm{H}_{2} \mathrm{PO}_{4}^{-}, \mathrm{HSO}_{4}^{-}$e $\mathrm{NO}_{3}^{-}$) foram adicionadas à solução incolor de AB-MB. Observou-se que somente a adição de $\mathrm{F}^{-}$ provocou o reaparecimento da banda solvatocrômica original em $571,0 \mathrm{~nm} \cdot{ }^{25} \mathrm{Em}$ outras palavras, a solução incolor de AB-MB somente retornou à cor violeta quando $\mathrm{o} F$ - foi adicionado (Figura 6). Conseqüentemente, o sistema estudado aqui representa uma estratégia alternativa eficiente, em comparação com outros estudos descritos na literatura, 18,23 para a detecção visual e quantitativa de fluoreto de um modo seletivo. 


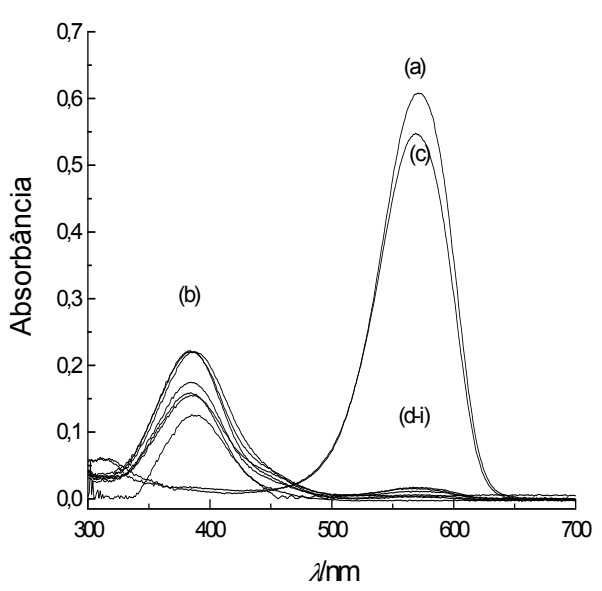

Figura 6 - Espectros de UV-vis de soluções em acetonitrila de (a) MB, (b) AB-MB e de AB-MB na presença de (c) F-, (d) $\mathrm{Cl}^{-}$, (e) $\mathrm{Br}$, (f) $\mathrm{I}^{-}$, (g) $\mathrm{H}_{2} \mathrm{PO}_{4}{ }^{-}$, (h) $\mathrm{HSO}_{4}^{-}$e (i) $\mathrm{NO}_{3}^{-}$como sais de tetrabutilamônio em concentração igual a $1,0 \times 10^{-4} \mathrm{~mol} / \mathrm{L}$. As concentrações de $\mathbf{M B}$ e $\mathbf{A B}$ foram $1,0 \times 10^{-5}$ e $2,78 \times 10^{-4} \mathrm{~mol} / \mathrm{L}$, respectivamente.

Foram realizados experimentos de titulação para quantificar a influência do aumento das concentrações de fluoreto nas soluções de AB-MB. Foi observado que a adição do ânion induziu o desaparecimento da banda em 385,9 nm, da solução AB-MB, com o aparecimento simultâneo da banda solvatocrômica da MB em 571,0 nm (Figura 7). A presença do ponto isosbéstico em 470,1 nm também foi observada. As absorbâncias em 571,0 nm, como uma função da concentração de fluoreto, exibiram um comportamento quase linear até que as concentrações da $\mathbf{M B}$ e do fluoreto fossem as mesmas (Figura 8). Isto supre evidências importantes para o fato de que o fluoreto atua como um nucleófilo, deslocando a $\mathbf{M B}$ e formando uma espécie AB-F, em um mecanismo de substituição nucleofílica bimolecular. Um ajuste dos dados experimentais considerando $\mathbf{A B}$ e o ânion em uma estequiometria na razão 1:1 resultou um valor de constante igual a $(1,93 \pm 0,53) \times 10^{5} \mathrm{~L} \mathrm{~mol}^{-1} .{ }^{25,33}$

Um importante aspecto a ser considerado é que o experimento foi realizado com um grande excesso de $\mathbf{A B}$, mais de vinte e sete vezes em relação à $\mathbf{M B}$. Desde modo, em princípio, quando o F- é adicionado, pode reagir com $\mathbf{A B}$ ou com $\mathbf{A B}-\mathbf{M B}$ e, se o excesso de $\mathbf{A B}$ é considerado, a preferência inicial seria pelo $\mathbf{A B}$. Isso induziria a uma curva de titulação com perfil sigmóide, o que não é o caso, indicando que o $\mathrm{F}^{-}$reage preferencialmente com AB-MB em comparação com o AB. No entanto, os dados sugerem que, na espécie AB-MB, a MB tenha um duplo papel, fazendo com que o centro de boro seja mais eletrofílico que o $\mathbf{A B}$ e também atuando como um excelente grupo de saída.

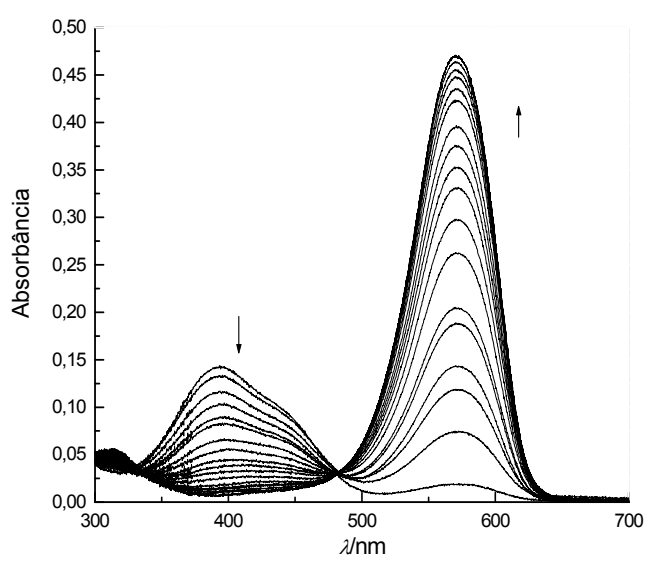

Figura 7 - Espectros de UV-vis correspondentes à titulação de AB-MB em acetonitrila a $25^{\circ} \mathrm{C}$ com quantidades crescentes de fluoreto de tetrabutilamônio. As concentrações de $\mathbf{A B}$ e $\mathbf{M B}$ foram $2,78 \times 10^{-4}$ e $1,0 \times 10^{-5} \mathrm{~mol} / \mathrm{L}$, respectivamente, e a concentração final de fluoreto foi de $8,2 \times 10^{-5} \mathrm{~mol} / \mathrm{L}$.

Além disso, é possível que a acetonitrila desempenhe um importante papel, interagindo com o centro borônico no $\mathbf{A B}$ e inibindo o acesso do fluoreto. É importante observar que o efeito mais importante do $\mathrm{F}^{-}$em comparação com outros ânions está relacionado com seu menor tamanho, maior densidade, e grande afinidade eletrônica, propriedades que favorecem uma interação forte com o centro borônico do AB. Estes aspectos têm sido realçados em outras publicações em relação à alta seletividade por $\mathrm{F}^{-}$em comparação com outros ânions, por parte de quimiossensores fluorogênicos e cromogênicos baseados no fenol. ${ }^{18,23}$

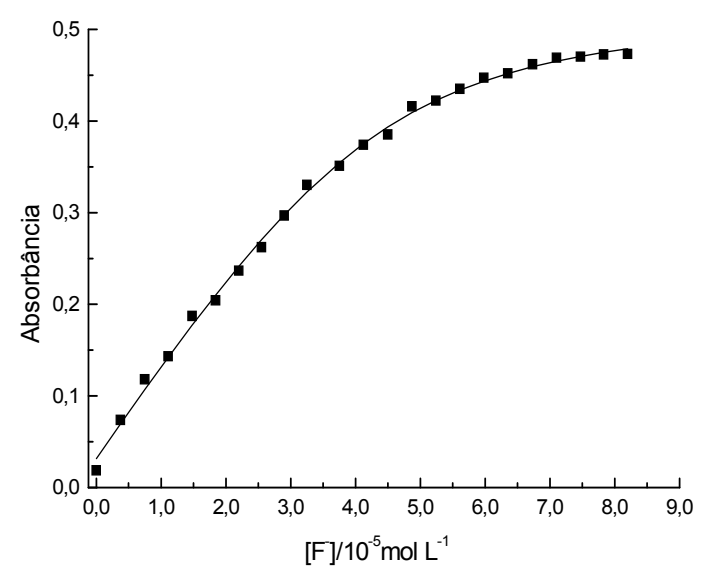

Figura 8 - Variação na absorbância em 571,0 nm proveniente do aparecimento da $\mathbf{M B}$ em acetonitrila a partir de uma solução de AB-MB pela adição de quantidades crescentes de fluoreto de tetrabutilamônio. $\mathrm{O}$ experimento foi realizado a $25^{\circ} \mathrm{C}$ e as concentrações de $\mathbf{M B}$ e AB foram de $1,0 \times 10^{-5}$ e $2,78 \times 10^{-4} \mathrm{~mol} / \mathrm{L}$, respectivamente. 
Separadamente, foi realizado um estudo que demonstrou que o cianeto pode também ser detectado eficientemente usando-se a mesma estratégia (Figura 9). Evidenciou-se que o cianeto atua como nucleófilo, assim como o fluoreto, deslocando a MB por meio do mecanismo de substituição nucleofílica bimolecular.

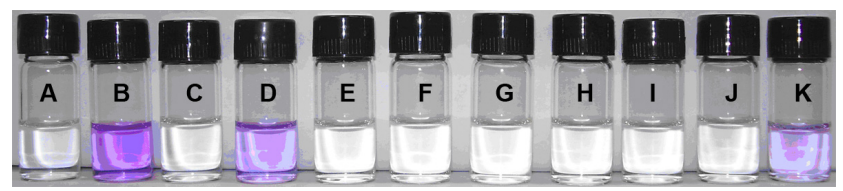

Figura 9 - Soluções de: (A) AB $\left(2,78 \times 10^{-4} \mathrm{~mol} / \mathrm{L}\right)$; (B) $\mathbf{M B}\left(1,0 \times 10^{-5}\right.$ $\mathrm{mol} / \mathrm{L})$; (C) AB-MB; e AB-MB na presença de: (D) CN; (E) Cl-; (F) $\mathrm{Br} ;(\mathrm{G}) \mathrm{I} ;$ ( $\mathrm{H}) \mathrm{H}_{2} \mathrm{PO}_{4} ;$; (I) $\mathrm{HSO}_{4} ;$; (J) $\mathrm{NO}_{3} ; \mathrm{K}$ ) todos os ânions juntos. Os ânions encontram-se na concentração de $1,0 \times 10^{-4} \mathrm{~mol} / \mathrm{L}$.

\subsection{Montagem de um quimiossensor cromogênico para} álcoois

Ao adicionar-se um pequeno volume de metanol ou etanol ao complexo AB-MB em acetonitrila, pode-se observar uma mudança significativa na coloração da solução, que passa de incolor para rosa avermelhada (Figuras 10 e 11). Já para os ensaios feitos com o propan-2-ol essa mudança de coloração leva alguns minutos para acontecer (Figura 12) e para o 2-metil-propan-2-ol não ocorre variação alguma, mesmo deixando-se o álcool em contato com o complexo por seis horas. Os resultados demonstram que os álcoois primários, que apresentam menor impedimento estéreo, conseguem mais facilmente atacar nucleofilicamente o centro de boro e substituir a MB. Os álcoois secundários, que apresentam um impedimento estéreo maior, atacam o centro de boro com dificuldade, requerendo mais tempo para se observar mudança na coloração. Finalmente, os álcoois terciários não atacam nucleofilicamente o centro de boro (ou o atacam muito lentamente) por apresentarem grande impedimento estéreo. Assim, o quimiossensor aqui apresentado oferece a possibilidade de promover, por uma variável cinética, a distinção visual entre álcoois primários, secundários e terciários. O Esquema 2 apresenta o sistema estudado como quimiossensor cromogênico para álcoois, que se encontra em consonância com os resultados obtidos.

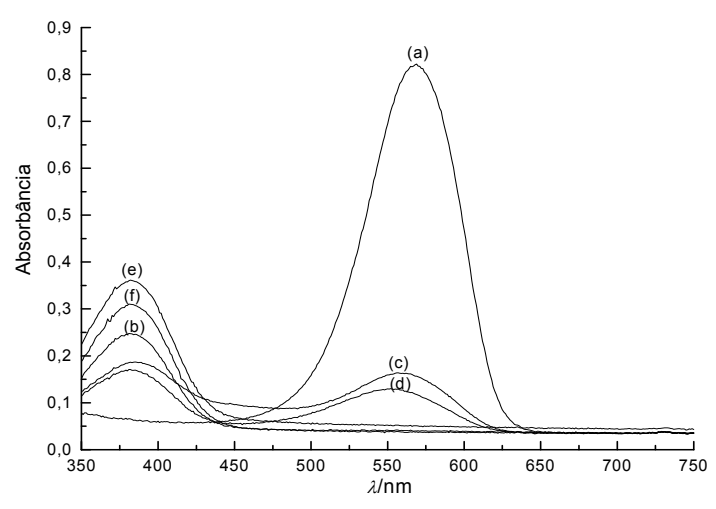

Figura 10 - Espectros de UV-vis de (a) MB, (b) AB-MB em acetonitrila com a presença de (c) metanol, (d) etanol, (e) propan-2-ol e (f) 2-metil-propan-2-ol. As concentrações de MB e AB são $1,9 \times 10^{-5}$ e $9,8 \times 10^{-4} \mathrm{~mol} / \mathrm{L}$, respectivamente, enquanto as concentrações para cada álcool foram iguais a $0,26 \mathrm{~mol} / \mathrm{L}$.

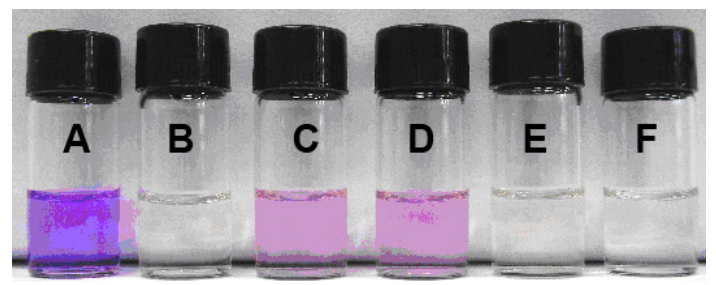

Figura 11 - Soluções em acetonitrila de (A) MB, (B) AB-MB e de AB-MB na presença de (C) metanol, (D) etanol, (E) propan-2-ol e (F) 2-metil-propan-2-ol. As concentrações de $\mathbf{M B}$ e $\mathbf{A B}$ são $1,9 \times 10^{-5}$ e $9,8 \times 10^{-4} \mathrm{~mol} / \mathrm{L}$, respectivamente. A concentração para cada álcool foi igual a $0,26 \mathrm{~mol} / \mathrm{L}$. A foto foi feita imediatamente após a adição do propan-2-ol (ver texto).

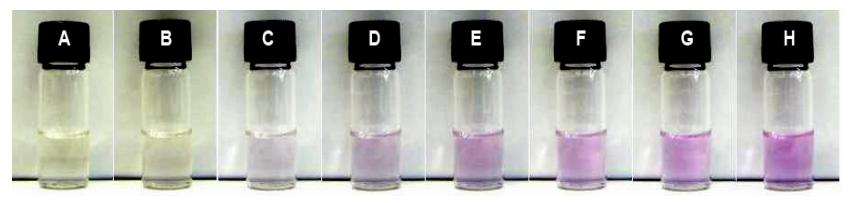

Figura 12 - Soluções em acetonitrila de (A) AB-MB e de AB-MB com propan-2-ol em (B) $0 \mathrm{~min}$, (C) 1min, (D) $2 \mathrm{~min}$, (E) $3 \mathrm{~min}$, (F) 4 min, (G) 5 min e (H) $10 \mathrm{~min}$.

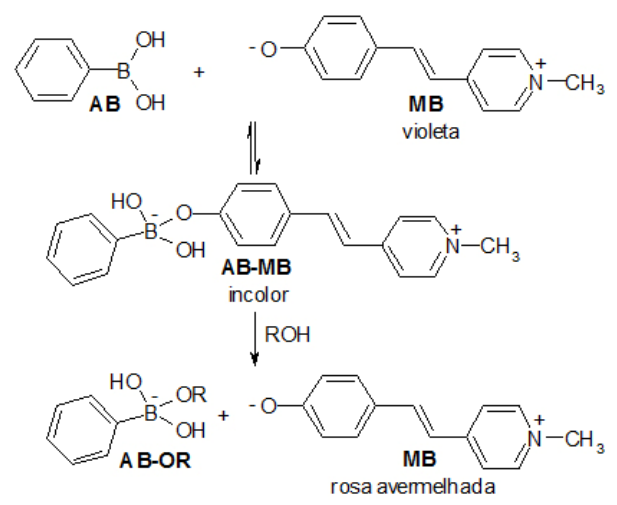

Esquema 2 


\section{Conclusões}

A obtenção de quimiossensores cromogênicos para a detecção visual e quantitativa de fluoreto, cianeto e álcoois é de importância pelas suas aplicações potenciais em diferentes áreas do conhecimento. Mostrou-se aqui que a reação de $\mathbf{M B}$ com o $\mathbf{A B}$ em excesso levou à formação de uma espécie incolor ABMB, a qual está apta a atuar como um quimiossensor cromogênico para fluoreto e para cianeto. A estratégia estudada aqui combina a concepção de quimiossensores baseados nos ensaios de deslocamento com o planejamento dos quimiossensores fundamentados na formação/quebra de ligações covalentes. Considerando-se que ácidos borônicos são receptores muito importantes que ligam seletivamente cianeto, ${ }^{29}$ os ensaios apresentados aqui podem ser facilmente modificados para provir quimiossensores cromogênicos para este analito. $\mathrm{O}$ estudo efetuado também demonstrou que ácidos borônicos associados a corantes solvatocrômicos, tais como a $\mathbf{M B}$ e o $\mathbf{C R}$ podem ser utilizados como quimiossensores cromogênicos bastante versáteis para a detecção visual e quantitativa de álcoois. Finalmente, os estudos efetuados sugerem ainda que a natureza dos grupos substituintes no anel aromático dos ácidos borônicos, o meio e a estrutura do indicador devem ser muito importantes para determinar a versatilidade e a eficiência desta nova classe de quimiossensores cromogênicos.

5. Agradecimentos: Os autores gostariam de agradecer aos programas PIBIC/CNPq, PIBIC/FURB, à Capes, ao CNPq e à FURB pelo auxílio financeiro concedido.

\section{Referências}

1. Fluorescent Chemosensors for Ion and Molecule Recognition, ed. por Czarnik, A.W. ACS Symposium Series 538, American Chemical Society, Washington, D.C., 1993.

2. Fabbrizzi, L.; Poggi, A. Chem. Soc. Rev. 1995, 197.

3. Wiskur, S. L.; Ait-Haddou, H.; Lavigne, J. J.; Anslyn, E. V. Acc. Chem. Res. 2001, 34, 963.

4. (a) Suksai, C.; Tuntulani, T. Chem. Soc. Rev. 2003, 32, 192; (b) Suksai, C.; Tuntulani, T. Top. Curr. Chem. 2005, 255, 163.

5. Sessler, J. L.; Camiolo, S.; Gale, P. A. Coordin. Chem. Rev. 2003, 240, 17 .

6. (a) Martínez-Máñez, R.; Sancenón, F. Chem. Rev. 2003, 103, 4419; (b) Martínez-Máñez, R.; Sancenón, F. J. Fluoresc. 2005, 15, 267; (c) Martínez-Máñez, R.; Sancenón, F. Coord. Chem. Rev. 2006, $250,3081$.
7. Kubik, S.; Reyheller, C.; Stüwe, S. J. Inclusion Phenom. Macrocyclic Chem. 2005, 52, 137.

8. Gunnlaugsson, T.; Glynn, M.; Tocci, G. M.; Kruger, P. E.; Pfeffer, F. M. Coord. Chem. Rev. 2006, 250, 3094

9. (a) Callan, J.F.; de Silva, A.P.; Magri, D.C. Tetrahedron 2005, 61, 8551; (b) Magri, D.C.; Vance, T.P.; de Silva, A.P. Inorg. Chim. Acta 2007, 360, 751

10. Anzenbacher Jr., P.; Nishiyabu, R.; Palacios, M.A. Coord. Chem. Rev. 2006, 250, 2929.

11. O'Neil, E.J.; Smith, B.D. Coord. Chem. Rev. 2006, 250, 3068.

12. Gunnlaugsson, T.; Glynn, M.; Tocci, G.M.; Kruger, P.E.; Pfeffer, F.M. Coord. Chem. Rev. 2006, 250, 3094.

13. Amendola, V.; Esteban-Gómez, D.; Fabbrizzi, L.; Licchelli, M. Acc. Chem. Res. 2006, 39, 343.

14. Prodi, L. New J. Chem. 2005, 29, 20.

15. Löhr, H.G.; Vögtle, F. Acc. Chem. Res. 1985, 18, 65.

16. Machado, V.G.; Machado, C.; Nascimento, M. da G.; Rezende, M.C. Quim. Nova 1996, 19, 523.

17. (a) Mohr, G. J. Chem. Eur. J. 2004, 10, 1082; (b) Mohr, G.J. Anal. Biochem. Chem. 2006, 386, 1201.

18. Ver por exemplo: (a) Lee, K.H.; Lee, H.-Y.; Lee, D.H.; Hong, J.-I. Tetrahedron Lett. 2001, 42, 5447; (b) Lee, D.H.; Im, J.H.; Lee, J.-H.; Hong, J.-I. Tetrahedron Lett. 2002, 43, 9637; (c) Won, D.-H.; Lee, C.-H. Tetrahedron Lett. 2003, 44, 6695; (d) Camiolo S.; Galé, P.A.; Hursthouse, M.B.; Light, M.E.; Warriner, C.N. Tetrahedron Lett. 2003, 44, 1367; (e) Jose, D.A. Kumar, D.K.; Ganguly, B.; Das, A. Org. Lett. 2004, 6, 3445; (f) Morey, J.; Orell, M.; Barcelò, M.A.; Deyà, P.M. Costa, A.; Ballester, P. Tetrahedron Lett. 2004, 45, 1261; (g) Costero, A.M.; Bañuls, M.J.; Aurell, M.J.; Ward, M.D.; Argent, S. Tetrahedron 2004, 60, 9471; (h) Liu, S.-Y.; He, Y.-B.; Qing, G.Y.; Xu, K.-X.; Qin, H.-J. Tetrahedron Asym. 2005, 16, 1527; (i) Kao, T.-L.; Wang, C.-C.; Pan, Y.-T.; Shiao, Y.-J.; Yen, J.-Y.; Shu, C.-M.; Lee, G.-H.; Peng, S.-M.; Chung, W.-S. J. Org. Chem. 2005, 70, 2912; (j) Kádár, M.; Biró, A.; Tóth, K.; Vermes, B.; Huszthy, P. Spectrochim. Acta, Part A 2005, 62, 1032; (k) Lee, H.G.; Lee, J.-E.; Choi, K.S. Inorg. Chem. Commun. 2006, 9, 582; (l) Wagner-Wysiecka, E.; Jamrógiewicz, M.; Fonari, M.S.; Biernat, J.F. Tetrahedron 2007, 63, 4414; (m) Puyol, M.; Encinas, C.; Rivera, L.; Miltsov, S.; Alonso, J. Dyes Pigm. 2007, 73, 383; (n) Rivera, L.; Puyol, M.; Miltsov, S.; Alonso, J. Anal. Bioanal. Chem. 2007, 387, 2111.

19. Reichardt, C. Solvents and Solvent Effects in Organic Chemistry, 3a. ed. VCH: Weinheim, 2003; cap. 6 e 7.

20. Suppan, P.; Ghoneim, N. Solvatochromism, 1a. ed. Royal Society of Chemistry: Cambridge, 1997.

21. (a) Reichardt, C. Chem. Rev. 1994, 94, 2319; (b) Reichardt, C. Pure Appl. Chem. 2004, 76, 1903. (c) Reichardt, C. Green Chem. 2005, 7, 339 .

22. (a) Brooker, L. G. S.; Keyes, C. H.; Sprague, R. H.; Van Dyke, R.H.; Van Zandt, G.; White, F. L.; Cressman, H. W. J.; Dent, S. G. J. Am. Chem. Soc. 1951, 73, 5332; (b) Brooker, L. G. S.; Keyes, C. H.; Heseltine, D. W. J. Am. Chem. Soc. 1951, 73, 5350; (c) Cavalli, V.; da Silva, D.C.; Machado, C.; Machado, V.G.; Soldi, V. J. Fluoresc. 2006, 16, 77

23. Reis, D.C.; Machado, C.; Machado, V.G. Tetrahedron Lett 2006, 47, 9339 . 
24. Linn, M.M.; Poncio, D.C.; Machado, V.G. Tetrahedron Lett. 2007, 48,4547 .

25. Nicolini, J.; Testoni, F. M.; Schuhmacher, S. M.; Machado, V. G. Tetrahedron Lett. 2007, 48, 3467.

26. Ribeiro, E.A.; Cadorin, L.; Machado, V.G. Trabalho em andamento.

27. Badugu, R.; Lakowicz, J. R.; Geddes, C.D. Talanta 2005, 65, 762.

28. Ver por exemplo: (a) DiCesare, N.; Lakowicz, J.R. Org. Lett. 2001, 3, 3891; (b) Kawanishi, T.; Romey, M.A.; Zhu. P.C.; Holody, M.Z. Shinkai, S. J. Fluoresc. 2004, 14, 499; (c) Zhao, J.; Fyles, T.M.; James, T.D. Angew. Chem., Int. Ed. Engl. 2004, 43, 3461; (d) Badugu, R.; Lakowicz, J.R.; Geddes, C.D. Talanta 2005, 66, 569; (e) Badugu, R.; Lakowicz, J.R.; Geddes, C.D. Dyes Pigm. 2006, 68, 159;

29. (a) Badugu, R.; Lakowicz, J.R.; Geddes, C.D. Anal. Biochem. 2004 327, 82; (b) Badugu, R.; Lakowicz, J.R.; Geddes, C.D. Curr. Anal. Chem. 2005, 1, 157; (c) Badugu, R.; Lakowicz, J.R.; Geddes, C.D. J. Am. Chem. Soc. 2005, 127, 3635.
30. Furniss, B.S.; Hannaford, A.J.; Smith, P.W.G.; Tatchell, A.R. Vogel's Textbook of Practical Organic Chemistry, 5a. ed., Longman, London, 1989.

31. Osterby, B.R.; McKelvey, R.D. J. Chem. Educ. 1996, 73, 260.

32. Minch, M.J.; Shah, S.S. J. Chem. Educ. 1977, 54, 709.

33. Valeur, B.; Pouget, J.; Bourson, J.; Kaschke, M.; Ernsting, N.P. J. Phys. Chem. 1992, 96, 6545.

34. ORGANIKUM, Química Orgânica Experimental, traduzido por Rauter, A.P.; Herold, B.J., 2a. ed., Fundação Calouste Gulbenkian, Lisboa, 1997, p. 862.

35. http://www.qca.ibilce.unesp.br/prevencao/protocolo.htm (acessado em 26/05/2007).

36. (a) Ricken, I.; Silva, M. A. R.; Machado, V. G. J. Phys. Org. Chem. 2002, 15, 420; (b) Bevilaqua, T.; da Silva, D. C.; Machado, V. G. Spectrochim. Acta, Part A 2004, 60, 951. 